\title{
Natural Multimerization Rules the Performance of Affinity-Based Physical Hydrogels for Stem Cell Encapsulation and Differentiation
}

\author{
Cláudia S. M. Fernandes, André L. Rodrigues, Vitor D. Alves, Tiago G. Fernandes, Ana Sofia Pina,* \\ and Ana Cecília A. Roque*
}

ABSTRACT: Tissue engineering and stem cell research greatly benefit from cell encapsulation within hydrogels as it promotes cell expansion and differentiation. Affinity-triggered hydrogels, an appealing solution for mild cell encapsulation, rely on selective interactions between the ligand and target and also on the multivalent presentation of these two components. Although these hydrogels represent a versatile option to generate dynamic, tunable, and highly functional materials, the design of hydrogel properties based on affinity and multivalency remains challenging and unstudied. Here, the avidin-biotin affinity pair, with the highest reported affinity constant, is used to address this challenge. It is demonstrated that the binding between the affinity hydrogel components is influenced by the multivalent display selected. In addition, the natural multivalency of the interaction must be obeyed to yield robust multicomponent synthetic protein hydrogels. The hydrogel's resistance to erosion depends on the right stoichiometric match

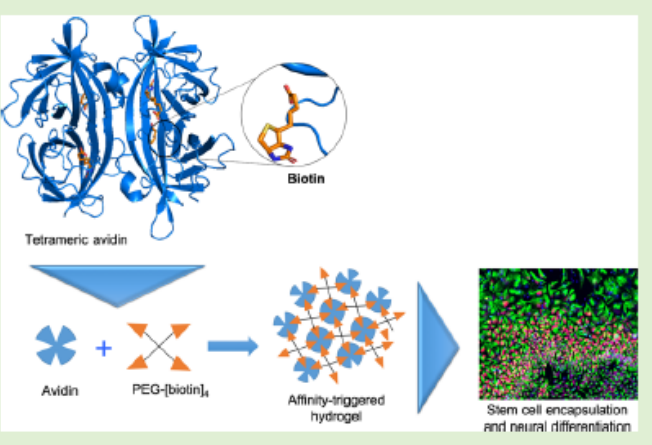
between the hydrogel components. The developed affinity-triggered hydrogels are biocompatible and support encapsulation of induced pluripotent stem cells and their successful differentiation into a neural cell line. This principle can be generalized to other affinity pairs using multimeric proteins, yielding biomaterials with controlled performance.

\section{INTRODUCTION}

Interfacing chemistry and biology has generated incredible biomedical tools, in particular, in the field of biomaterials for cell encapsulation and differentiation. ${ }^{1-3}$ Pluripotent stem cells are ideal for personalized cell therapies because they can potentially differentiate into any cell type of the human body. $^{4-6}$ Stem cells demonstrate good clinical results in alleviating, for example, the motor symptoms of neurological disorders such as Parkinson's disease. ${ }^{4}$ However, cell replacement therapies are still limited by the large number of high-quality cells needed as in vivo survival of transplanted cells and functional integration are typically very low. ${ }^{6}$ As an example, only $1-5 \%$ of midbrain dopaminergic neurons used for cell replacement therapy treatment survive after striatal transplantation. ${ }^{7}$ To address this issue, cell encapsulation has been used to promote cell expansion and differentiation.

Cell encapsulation is typically achieved with biomaterials mimicking the in vivo conditions conferred by the extracellular matrix (ECM). The ECM is composed of different multifunctional proteins that provide cells with biochemical and structural cues for their growth, multiplication, and differentiation. ${ }^{8}$ Several natural materials have been used to provide cells with such cues. In particular, Matrigel is a commercially available cell culture substrate ${ }^{9}$ used as a matrix for in vitro cell and tissue culture despite its nonreproducible and poorly defined composition. ${ }^{10-12}$ In addition, it can also lose its biological activity during processing ${ }^{13}$ and be immunogenic. ${ }^{8,14}$ These disadvantages have led many scientists to develop innovative strategies to mimic the ECM, which have been extensively reviewed elsewhere. ${ }^{8,15-17}$

Affinity-triggered hydrogels are a class of protein-based hydrogels that closely resemble the dynamic behavior of the $\mathrm{ECM}^{18}$ as they can be tailored toward biocompatibility, hydrophilicity, and biodegradability, while also tuning the porosity, mechanical properties, and rate of degradation. ${ }^{14,19,20}$ The wide range of available binding constants from known affinity pairs, the selective molecular recognition of affinity interactions, and the existence of diverse multivalent systems to display the ligand and the receptor-from fully biological to synthetic-make affinity-triggered hydrogels a versatile tool to generate controllable, dynamic, tunable, and highly functional materials. ${ }^{21}$ Various ligand/receptor affinity pairs have been explored to assemble hydrogels for tissue engineering

Received: March 31, 2020

Revised: $\quad$ May 28, 2020

Published: June 23, 2020 
applications, namely, TIP1/TIP1-binding peptides, ${ }^{22,23} \mathrm{WW} /$ proline-rich peptides, ${ }^{24-28}$ and gyrase/coumermycin, ${ }^{29}$ as well as host/guest supramolecular pairs. ${ }^{30,31}$ Multivalency is achieved through (i) the presentation of the ligand or receptor as tandem displays (e.g., recombinant expression of the ligand displayed in tandem with suitable linkers), (ii) the chemical conjugation of the ligand and/or receptor to multimeric polymers [e.g., branched polyethyleneglycol (PEG)], or (iii) the use of naturally occurring multimeric ligands or receptors. The reported examples of affinity-triggered hydrogels are based on trial and error approaches. First, it is assumed that higher component multivalency promotes cross-linking and hydrogels robustness. ${ }^{32}$ Second, only the observed binding constant of the ligand-receptor in solution is considered and not the binding interactions established in the real hydrogel system where multivalent polymers and linkers exist, giving rise to stereo-hindrance and/or avidity effects. The importance of establishing design rules to yield multicomponent protein hydrogels with predictable properties has been acknowledged in systems using tandem display of engineered protein components. ${ }^{25,33}$ However, considering the palette of multimeric proteins that nature has to offer, it is inspirational to further take these examples toward biomaterials engineering.

The natural avidin-biotin affinity pair has the highest reported affinity constant (up to $10^{15} \mathrm{M}^{-1}$ ) 34,35 and is a valuable tool in innumerable applications. ${ }^{36}$ Avidin $(67 \mathrm{kDa})$ is a naturally occurring tetrameric protein, whereas biotin is a small molecule ( $244 \mathrm{Da}$ ) that can be chemically conjugated to different matrices. The interaction between avidin and biotin is unaffected by temperature, $\mathrm{pH}$, organic solvents, and denaturing agents, which makes this affinity pair an extremely interesting platform to generate stable chemical-biology interfaces. The affinity pair avidin-biotin promotes crosslinking in multicomponent hydrogels, where biotin multivalency was given by linear $\mathrm{PEG}^{34,37}$ or hyaluronic acid. ${ }^{38}$ In these pioneering examples, the strong interaction between avidin and biotin was successfully explored to generate hydrogels, but the affinity and avidity present in the multicomponent system were disregarded during material design.

Here, it is shown that the natural multivalency of the interaction between avidin and biotin can be mimicked in hydrogel assembly. This is achieved by tuning the multivalent presentation of the synthetic component (biotin-derivatized PEG), yielding materials with controlled performance. Such materials, which self-assemble instantaneously, encapsulate pluripotent stem cells and support neural commitment under defined xeno-free conditions, by ensuring cell expansion and differentiation. This work provides the design rules for affinitybased hydrogels, while also opening opportunities in the field of neural cell replacement therapy.

\section{MATERIALS AND METHODS}

2.1. Materials. Linear PEG functionalized with the N-hydroxysuccinimide (NHS) moiety (1120000-2) was purchased from Rapp Polymere. The molecules four-arm PEG functionalized with the NHS moiety (SUNBRIGHT PTE-200HS) and eight-arm PEG functionalized with the NHS moiety (SUNBRIGHT HGEO-200GS) were purchased from NOF Europe. Pierce avidin (21128) was purchased from Thermo Fisher Scientific. Biotin cadaverine (RL-2030) was acquired from Iris Biotech and Spectra/Por 7 dialysis tubing $10 \mathrm{kDa}$ MWCO (132120) from Spectrum. The induced pluripotent stem cell (iPSC) medium used was TeSR2 basal medium (\#05861) from StemCell Technologies; Dulbecco's modified Eagle's medium
(DMEM; high glucose; 12800-082), fetal bovine serum (FBS; 10270-106), and (3-(4,5-dimethylthiazol-2-yl)-2,5-diphenyltetrazolium bromide) (MTT; M6494) were purchased from Life Technologies. Fibroblast cells [NCTC clone 929 (L cell, L-929, derivative of Strain L) ATCC CCL-1] were purchased from ATCC.

2.2. Methods. 2.2.1. Synthesis and Characterization of Biotinylated PEG Oligomers. Biotin cadaverin, an amine-terminated biotin, was used to functionalize linear, four-arm, and eight-arm PEG molecules with terminal NHS groups. The PEG molecules were dissolved in phosphate-buffered saline (PBS; $20 \mathrm{mM}$ sodium phosphate, $150 \mathrm{mM} \mathrm{NaCl}, \mathrm{pH}$ 7.4). PEG solutions were then mixed with a $10 \mathrm{M}$ excess of biotin regarding the NHS groups of the PEG molecules. For example, $0.1 \mathrm{~g}$ of PEG-[NHS $]_{4}$ was dissolved in 1 $\mathrm{mL}$ of PBS, and $0.066 \mathrm{~g}$ of biotin cadaverin was dissolved in $1 \mathrm{~mL}$ of PBS. Both solutions were mixed and incubated for $16 \mathrm{~h}$ at $4{ }^{\circ} \mathrm{C}$ with rotational agitation $(40 \mathrm{rpm})$ and then dialyzed against water using a dialysis membrane with a molecular weight cutoff of $10 \mathrm{kDa}$ at room temperature. After dialysis, the biotin-modified PEG molecules were frozen at $-80^{\circ} \mathrm{C}$ and lyophilized.

The biotin-modified PEG molecules were characterized by Fourier transform infrared-attenuated total reflection (FTIR-ATR) and inductively coupled plasma (ICP). FTIR-ATR spectra (16 scans) were recorded in the range $400-4000 \mathrm{~cm}^{-1}$ on a PerkinElmer Spectrum Two FT-IR spectrometer, using the UATR Two module. Samples were analyzed using an L160-1742 tip, with a force gauge of $80-85$. Biotin has one sulfur element in its structure, and ICP was used to quantify the amount of sulfur in the samples. Samples ( $1 \mathrm{mg} /$ $\mathrm{mL}$ in water) were analyzed on a Horiba Jobin Yvon ULTIMA sequential ICP and Horiba Jobin Yvon ICP Analyst 5.4 software, using the monochromator with a Czerny Turner spectrometer and argon. The estimated degree of functionalization of the linear, fourarm, and eight-arm biotin-functionalized PEG molecules was $(97 \pm$ $3) \%$ for PEG-[biotin] $]_{v}(109 \pm 9) \%$ for PEG-[biotin $]_{4}$, and $(95 \pm$ 2)\% for PEG-[biotin $]_{8}$.

2.2.2. Affinity Constant Determination. Avidin was conjugated with fluorescein isothiocyanate (FITC) to allow the determination of the affinity constant by microscale thermophoresis (MST). FITC was dissolved in a small volume of DMF, to a total of 25-excess molar to the amount of avidin. The previous solution was added to the avidin solution $(2 \mathrm{mg} / \mathrm{mL}$ in $0.1 \mathrm{M}$ sodium carbonate-bicarbonate $\mathrm{pH} 9.1)$. The reaction occurred for $24 \mathrm{~h}$ at $4{ }^{\circ} \mathrm{C}$, with agitation $(40 \mathrm{rpm})$. To separate nonreacted fluorescein from fluorescently probed protein, the mixture was dialyzed against PBS using a dialysis membrane with a molecular weight cutoff of $10 \mathrm{kDa}$. The protein concentration and the efficiency of FITC labeling were determined according to the supplier's instructions. The final protein concentration was calculated as $18.5 \mu \mathrm{M}$ with a modification of $1.4 \mathrm{~mol}$ fluorescein $/ \mathrm{mol}$ avidin.

The affinity constants between PEG-biotin molecules and fluorescently labeled avidin were determined by MST. The FITCavidin solution was diluted to $60 \mathrm{nM}$ with PBS. The biotinylated PEG molecules were dissolved in PBS, and a series of sixteen 1:2 serial dilutions were prepared in the same buffer, with a range of concentrations between 2.5 and $7.8 \times 10^{-5} \mathrm{mM}$, to a total volume of $20 \mu \mathrm{L}$. Each ligand dilution was mixed with $20 \mu \mathrm{L}$ of FITC-avidin solution and loaded in appropriate capillaries in independent triplicate (Monolith NT.115 Standard Capillaries). The equipment used was a Monolith NT.115 instrument (NanoTemper Technologies), working at an ambient temperature of $25{ }^{\circ} \mathrm{C}$, with parameters adjusted to $20 \%$ light-emitting diode power and $20 \%$ MST power. The affinity constant is calculated using the software, by fitting the experimental data to the Hill model, with a response evaluation at $10 \mathrm{~s}$.

2.2.3. Hydrogel Formation and Characterization. Biotinylated PEG oligomers and avidin were both dissolved separately in PBS. Equal volumes of both components were mixed in order to have final concentrations of each component of $0.1,0.5,1,2.5,5$, and $10 \%$ (w/ v). Gelation of the mixed components was observed immediately.

To assess the erosion profile of the assembled gels, $50 \mu \mathrm{L}$ hydrogels were formed. The weight of the hydrogel was recorded at the beginning of the study. PBS was added to the vial containing the hydrogel and completely removed after $10 \mathrm{~min}$. The new weight was 
measured, and fresh PBS was added to the vial. This was repeated until a maximum of 3 months every 5 days, in duplicate.

To assess the binding competition between free biotin and PEGconjugated biotin in hydrogels, the hydrogel $(50 \mu \mathrm{L})$ was formed, and after $16 \mathrm{~h}$, it was immersed in a solution containing $2 \mathrm{mg}$ biotin $/ \mathrm{mL}$ in PBS. The erosion profile was assessed by weight measurements for 15 days.

The rheological properties of the hydrogels were studied in a HAAKE MARS III controlled stress rheometer using parallel serrated plates with a diameter of $20 \mathrm{~mm}$ and a gap of $0.25 \mathrm{~mm}$ at $20 \pm 0.5^{\circ} \mathrm{C}$. The hydrogels were formed in a $3 \mathrm{D}$ printed mold with $8 \mathrm{~mm}$ diameter and $1 \mathrm{~mm}$ height, with a total volume of $50 \mu \mathrm{L}$. A shear stress sweep was carried out at constant frequency $(1 \mathrm{~Hz})$ to determine the linear viscoelastic region, where no variation of $G^{\prime}$ (storage modulus) and $G^{\prime \prime}$ (loss modulus) was observed. The viscoelastic properties $\left(G^{\prime}\right.$ and $G^{\prime \prime}$ ) of the hydrogels were determined by frequency sweep experiments $(0.01-100 \mathrm{~Hz})$ at the constant stress value within the linear viscoelastic region (Figure S4). A constant stress of $1 \mathrm{~Pa}$ was used in the frequency sweeps of four-arm $2.5 \%$ and four-arm $5 \%$ samples, and a constant stress of $0.5 \mathrm{~Pa}$ was used for the eight-arm $2.5 \%$ sample. Before measurements, a thin layer of low-viscosity paraffin oil was used to cover the free surface of the rheometer plate to prevent evaporation of the solvent. The assay was performed in duplicates.

Evidence of new interactions established between the hydrogel components was assessed by FTIR-ATR spectra (16 scans) of the hydrogels, recorded in the range $400-4000 \mathrm{~cm}^{-1}$ on a PerkinElmer Spectrum Two FT-IR spectrometer, using the UATR Two module (L160-1742 tip, with a force gauge of 0 or close to 0 ).

The morphology of the hydrogels was characterized by scanning electron microscopy (SEM). Hydrogels were prepared, as described previously, with a total volume of $10 \mu \mathrm{L}$ over a glass slide. The sample was frozen at $-20{ }^{\circ} \mathrm{C}$ and lyophilized. Samples were coated with a 15 $\mathrm{nm}$ layer of iridium using a Quorum evaporator and then analyzed in a Carl Zeiss AURIGA CrossBeam FIB-SEM workstation.

2.2.4. Hydrogel Biocompatibility. The biocompatibility of the hydrogel was assessed by indirect and direct toxicity tests, according to the guidelines of the International Organization for Standardization $^{39,40}$ and as previously described. ${ }^{28}$

For the indirect test, the L929 mouse fibroblast cell line was seeded at a density of $80,000 \mathrm{cell} / \mathrm{cm}^{2}$ in a 24-well culture plate, corresponding to 160,000 cells/well. The cells were covered with $0.5 \mathrm{~mL}$ of complete DMEM with $10 \%(\mathrm{v} / \mathrm{v})$ FBS, $2 \mathrm{mM}$ glutamine, and $1 \%(\mathrm{v} / \mathrm{v})$ commercial mixture of antibiotics (Pen/Strep, 100 units $/ \mathrm{mL}$ penicillin, $100 \mu \mathrm{g} / \mathrm{mL}$ streptomycin, and $0.025 \mu \mathrm{g} / \mathrm{mL}$ Amphotericin B in sterile PBS) and incubated for $24 \mathrm{~h}$ at $37{ }^{\circ} \mathrm{C}$ and $5 \% \mathrm{CO}_{2}$. The components necessary to form the $2.5 \%(\mathrm{w} / \mathrm{v})$ hydrogel ( $5 \%$ avidin and $5 \%$ PEG-[biotin $]_{4}$ ) were dissolved in $12.5 \mu \mathrm{L}$ of PBS and maintained under UV light for $15 \mathrm{~min}$. Afterward, the hydrogel was formed in a well in a separated culture plate and incubated with $0.5 \mathrm{~mL}$ of Pen/Strep for $30 \mathrm{~min}$. Simultaneously, a piece of a latex glove was cut and sterilized with $0.5 \mathrm{~mL}$ of Pen/Strep solution. The supernatant was removed, and the materials were washed twice with $0.5 \mathrm{~mL}$ of sterile PBS and covered with $0.5 \mathrm{~mL}$ of the cell culture medium. The following day, cells were observed under an inverted optical microscope to confirm the formation of a monolayer of cells at around $80 \%$ confluency. The medium covering the cells was replaced by the medium maintained overnight with the materials. Cells were then incubated for an additional $24 \mathrm{~h}$ at $37^{\circ} \mathrm{C}$ and $5 \% \mathrm{CO}_{2}$. The next day, the morphology of the cells was checked under an inverted optical microscope. Then, the MTT solution was prepared as follows: (a) a $5 \mathrm{mg}$ (3-(4,5-dimethylthiazol-2-yl)-2,5-diphenyltetrazolium bromide) $/ \mathrm{mL}$ sterile PBS stock solution was prepared by mixing the solution using a vortex until complete dissolution and (b) the solution was diluted to $1 \mathrm{mg} / \mathrm{mL}$ in PBS. The cell medium was removed, and the wells were washed with $0.5 \mathrm{~mL}$ of PBS. A volume of $0.3 \mathrm{~mL}$ of $1 \mathrm{mg} / \mathrm{mL}$ MTT solution was added to each well and was incubated for $2 \mathrm{~h}$ at $37^{\circ} \mathrm{C}$. Afterward, the MTT solution was removed from the plate, and $1 \mathrm{~mL}$ of the MTT solvent $[10 \%(\mathrm{v} / \mathrm{v})$ isopropanol in $10 \mathrm{M} \mathrm{HCl}$ ] was added to each well. The plates were agitated for 5 min, and a volume aliquot of $0.2 \mathrm{~mL}$ was transferred to a transparent 96-well plate. The absorbance was quantified at $570 \mathrm{~nm}$ using a plate reader (Tecan). Using the control cells maintained in the culture medium only for reference, total cell viability was calculated according to eq 1 .

$$
\text { Viability }=\frac{\text { absorbance }(\text { sample })}{\text { absorbance }(\text { control })} \%
$$

For the direct biocompatibility test, the components necessary to form the hydrogel ( $5 \%$ avidin and $5 \%$ PEG-[biotin $]_{4}$ ) were dissolved in $12.5 \mu \mathrm{L}$ of PBS and put under UV light for $15 \mathrm{~min}$. The same sterilization procedure was performed on a piece of latex glove. The L929 fibroblast cell line was seeded at a density of $80,000 \mathrm{cell} / \mathrm{cm}^{2}$ in a 24-well culture plate, corresponding to 160,000 cells/well. The cells were covered with $0.5 \mathrm{~mL}$ of DMEM with $10 \% \mathrm{FBS}$ and incubated for $24 \mathrm{~h}$ at $37{ }^{\circ} \mathrm{C}$ and $5 \% \mathrm{CO}_{2}$. The following day, the cells were observed under an inverted optical microscope to confirm the formation of a monolayer (around or more than $80 \%$ confluence). The media covering the cells were removed and discarded. Afterward, the latex glove was put on top of the cells. In the case of the hydrogel, both solutions were simultaneously pipetted on top of the monolayer. The cells and materials were covered with $0.5 \mathrm{~mL}$ of cell media and were incubated for $24 \mathrm{~h}$ at $37^{\circ} \mathrm{C}$ and $5 \%$. The next day, the morphology and distribution of the cells near the materials were checked under the microscope.

2.2.5. Stem Cell Encapsulation and Differentiation. The Gibco human iPSC (hiPSC) line (from Thermo Fisher Scientific) was used for the experimental procedures. This is a viral integration-free hiPSC line generated using human cord blood-derived CD34+ progenitors with seven episomally expressed factors (Oct4, Sox2, Klf4, Myc, Nanog, Lin28, and SV40T). The hiPSCs were routinely cultured on Matrigel-coated plates in TeSR2 medium in a humidified $5 \% \mathrm{CO}_{2}$ incubator at $37^{\circ} \mathrm{C}$. The medium was daily refreshed, and when cells reached $80 \%$ confluence, the EDTA method was used to passage cells at a split ratio of $1: 4 .^{41}$

Prior to cell aggregation, cells were incubated with the culture medium supplemented with the $10 \mu \mathrm{M}$ Rho kinase inhibitor (ROCKi, Y-27632; STEMCELL Technologies) at $37^{\circ} \mathrm{C}$ for $1 \mathrm{~h}$. After culture medium removal, cells were washed with PBS and then incubated with Accutase solution (Sigma-Aldrich/Merck) at $37^{\circ} \mathrm{C}$ for $7 \mathrm{~min}$ for single-cell formation. Cells were flushed with Accutase solution and collected in a centrifuge tube with culture medium, for inactivation of enzymatic digestion, and centrifuged at $200 \mathrm{~g}$ for $3 \mathrm{~min}$. The cell pellet was resuspended in the culture medium supplemented with ROCKi (10 $\mu \mathrm{M})$ followed by seeding onto the AggreWell 400 plate (STEMCELL Technologies) with a cell density of $1.5 \times 10^{6}$ cells/ well $\left(1.3 \times 10^{3}\right.$ cells/microwell $)$ for a final volume of $1.5 \mathrm{~mL} /$ well. Before seeding, the AggreWell 400 plate was centrifuged at $2700 \mathrm{~g}$ for 5 min, and after seeding, it was centrifuged at $300 \mathrm{~g}$ for $3 \mathrm{~min}$. Cells settle by gravitation and self-aggregate to form $3 \mathrm{D}$ aggregates. Cells were kept in a $\mathrm{CO}_{2}$ incubator at $37{ }^{\circ} \mathrm{C}, 5 \% \mathrm{CO}_{2}$, and $20 \% \mathrm{O}_{2}$, and after the first $24 \mathrm{~h}$, the culture medium was changed daily without ROCKi. On day 2, cells were encapsulated in the avidin/PEG[biotin $]_{4}$ hydrogel. Before the encapsulation process, avidin is diluted in $21.75 \mu \mathrm{L}$ of TeSR2 medium with a final concentration of $10 \%$ (v/ v). The same procedure is performed for the PEG-[biotin] 4 . Afterward, the 3D aggregates are retrieved from the AggreWell plate and added to a falcon tube. The aggregates settled to the bottom, and the supernatant was discarded. Fresh media were added $(43.5 \mu \mathrm{L})$ to resuspend the aggregates. This volume was then divided in equal parts by the components $\mathrm{A}$ and $\mathrm{B}$, which were diluted to $5 \%$ (v/v). In a 24-well plate, $12.5 \mu \mathrm{L}$ of $\mathrm{A}$ and $\mathrm{B}$ was added to a well to allow the physical gelation of the hydrogel by self-assembly. This procedure was carried out using at least three replicates.

A LIVE/DEAD viability/cytotoxicity kit (Thermo Fisher Scientific) was used to assess the viability of expanded hiPSCs. Before the encapsulation process, the aggregates were incubated for $20 \mathrm{~min}$ with Calcein AM solution, according to the manufacturer's instructions. The aggregates were then encapsulated, and cell viability was assessed 
(A)

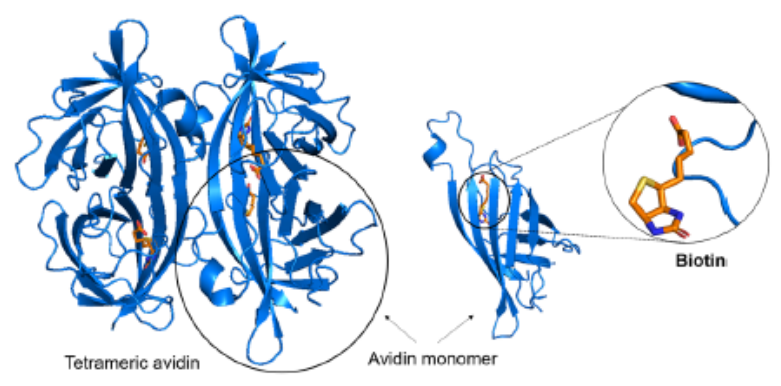

(C)

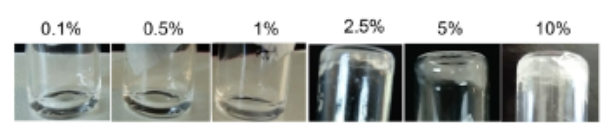

(D)

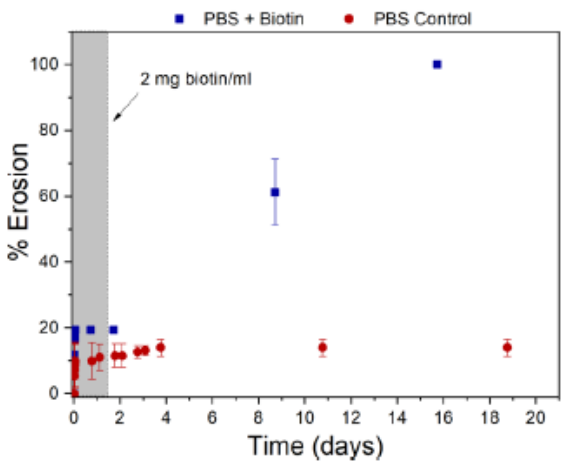

(B)
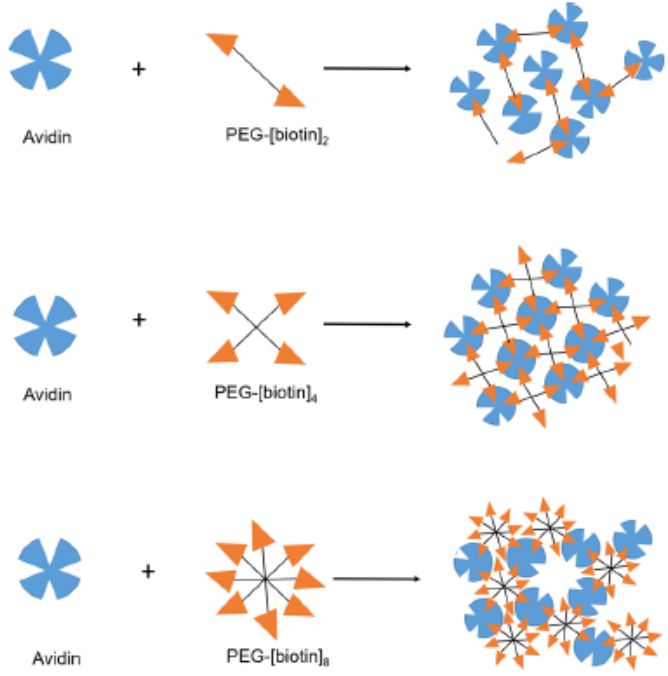

(E)

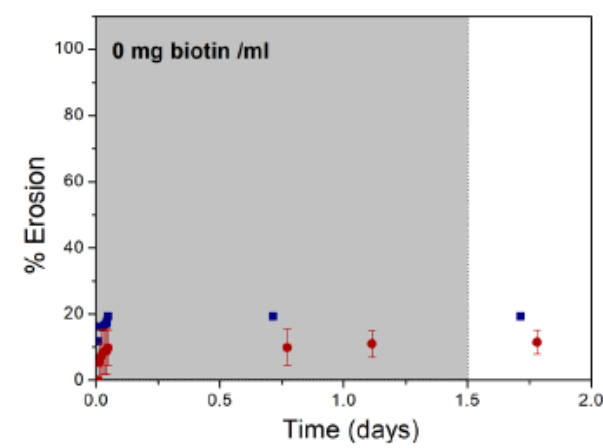

Figure 1. (A) Structure of tetrameric avidin, detailing the interaction between one unit of avidin with the ligand biotin (2AVI.pdb) (B) Schematic representation of an affinity-triggered hydrogel self-assembly based on the affinity pair avidin and biotin and their corresponding affinity constant, as determined by MST. (C) Images of the mixture between biotinylated four-arm PEG and free avidin at different concentrations: $0.1,0.5,1,2.5,5$, and $10 \%(\mathrm{w} / \mathrm{v})$. (D) Erosion profile of avidin/PEG-[biotin] ${ }_{4}$ hydrogels in the presence of PBS (15\% after 20 days) or PBS containing 2 mg biotin/ $\mathrm{mL}$ (100\% after 16 days). (E) Erosion profile at the beginning before adding $2 \mathrm{mg} / \mathrm{mL}$ biotin (stdev corresponds to three replicates).

through fluorescence microscopy. On day 5 of expansion, the encapsulated aggregates were recovered, and the same Calcein AM staining procedure was repeated to assess whether cells would maintain their viability. Nonencapsulated aggregates were used as controls. At least three replicates were used to measure the fluorescence intensities from the images using Fiji Image J. Two-way ANOVA tests were used to assess the statistical significance between conditions.

After 3 days of encapsulation, cells were harvested and replated on Matrigel-coated plates. In parallel assays, aggregates encapsulated for 2 days were induced to differentiate. To promote neural differentiation, TeSR 2 culture medium was replaced daily by Essential 6 medium supplemented with 1:200 (v/v) of Pen/Strep for a period of 14 days. Afterward, part of the encapsulated aggregates was harvested and part was replated onto laminin-coated plates for immunocytochemistry assays. In both cases, cells were fixed with $4 \%(\mathrm{w} / \mathrm{v})$ paraformaldehyde (PFA). Nonencapsulated aggregates were replated in the same manner and used as controls. For immunocytochemistry assays, the protocol is described elsewhere. ${ }^{42}$ Primary antibodies used for the immunocytochemistry assay comprised the pluripotency markers OCT4 (1:200; Millipore) and SOX2 (1:200; R\&D Systems) and the differentiation markers PAX6 (1:400, Covance), NESTIN (1:500, R\&D Systems), and ZO-1 (1:200, Novex). The secondary antibodies included goat anti-mouse IgG Alexa Fluor 488 or 546 (1:500) and goat anti-rabbit IgG Alexa Fluor 546 (1:500) from Invitrogen. Nuclei were counterstained using 4',6-diamidino-2phenylindole (DAPI). In the case of OCT4 and SOX2 staining, at least three replicates were used to measure the fluorescence intensities from the images using Fiji ImageJ. The percentage of cells expressing SOX2 and OCT 4 could be calculated based on the quantification of the mean fluorescence intensity in the red channel, which corresponds to the cells expressing the pluripotency markers OCT4 and SOX2, and of the blue channel (all cell nuclei counterstained with DAPI).

\section{RESULTS AND DISCUSSION}

3.1. Selection of Multivalent PEG-Biotin for Hydrogel Formation. In multicomponent protein hydrogels, as affinitytriggered hydrogels, gel assembly is promoted by the crosslinking between the multivalent components. This bottom-up approach takes advantage of the selective molecular recognition between the known affinity ligand-receptor pairs, in combination with multivalent display approaches to guide their autonomous self-assembly into robust nano-, micro-, and macrostructures. The simplest approach to generate multivalency includes the employment of natural multimeric proteins and their cognate ligands. In particular, avidin is a natural tetrameric protein with four biotin-binding sites. Biotin is a water-soluble vitamin acting as a cofactor in multiple metabolic pathways (Figure 1A, B). Avidin can be biotechnologically produced at high yields, ${ }^{43}$ and biotin is also widely available. This affinity pair is extremely interesting because of the high binding constants reported and because of the wide 
variety of avidin variants and avidin-binding peptides which further enlarge the tunability of the system.

In this work, avidin was employed as the multimeric protein and biotin cadaverin was conjugated in high yields (higher than $95 \%$ ) to multiarm $20 \mathrm{kDa}$ PEG molecules (linear, fourarm, and eight-arm) to generate multivalency. Branched PEG polymers are particularly suited to hydrogel formation-PEG polymers are hydrophilic, chemically well defined, and available in a wide range of molecular weights and chemistries. The success of PEG functionalization was confirmed by ICP and further observed by FTIR-ATR analysis of the PEG oligomers (Figure S1).

The assembly of affinity-triggered hydrogels implies the existence of molecular recognition and binding between each hydrogel component. The binding constant between free avidin and free biotin is well reported, ${ }^{34}$ but it is known that after immobilizing the ligand or the receptor into soluble or insoluble polymers in matrices, the binding constants are altered as the matrix itself plays a role in the molecular recognition event by generating a local microenvironment. ${ }^{28,46-48}$ Furthermore, the availability of the affinity pair elements to bind is modified, and several partitioning and stereo hindrance effects may occur.

In this work, biotin was conjugated to PEG oligomers (20 $\mathrm{kDa}$ ) with distinct multimerization (Figure 1A). MST (Figure S2) was used to determine the binding constants between avidin and each biotin-PEG oligomer. It was observed that the PEG-[biotin] $]_{4}$ presented the highest affinity constant $(1.6 \times$ $10^{8} \mathrm{M}^{-1}$ ). When decreasing (PEG-[biotin $]_{2}$ ) or increasing (PEG-[biotin $]_{8}$ ) the biotin multivalency, the affinity constant decreased 1 order of magnitude, presenting Ka values of $6.3 \times$ $10^{7}$ and $7.1 \times 10^{7} \mathrm{M}^{-1}$, respectively (Figure $2 \mathrm{~A}$ ). These results show the influence of PEG chain flexibility and steric hindrance in promoting the interaction between biotin and avidin. It also elucidates that the four-arm PEG displays the most appropriate multivalency and geometry to display free biotin molecules and promote the interaction with tetrameric avidin.

In fact, when mixing avidin and PEG-[biotin $]_{4}$ (equal mass amounts), a hydrogel was instantaneously formed. Each fourarm PEG molecule functionalized with biotin can bind to more than one molecule of the tetrameric avidin, which allows the cross-linking of biotinylated PEG oligomers via avidin-biotin interactions and, consequently, the formation of a network. Different concentrations were tested to assess the critical gelation concentration for the avidin/PEG-[biotin $]_{4}$ system: $0.1,0.5,1,2.5,5$, and $10 \%(\mathrm{w} / \mathrm{v})$ (Figure 1C). An increase in concentration resulted in an increase in viscosity of the mixture. Above $2.5 \%$, a physically cross-linked network was instantaneously formed, and a self-supporting hydrogel was observed by the vial inversion test. Below $2.5 \%$, the solution remained viscous. When PEG-[biotin $]_{8}$ was mixed with avidin at the same concentration (2.5\%), a self-supporting hydrogel was also formed. When linear biotinylated PEG was mixed with avidin at $2.5 \%$, no hydrogel was formed. Liu and colleagues $^{37}$ used $1.5 \mathrm{kDa}$ linear biotin-conjugated PEG and were able to observe the formation of a hydrogel; however, hydrogels were obtained at a much higher concentration (13.3\%). As such, in our work, the avidin/PEG-[biotin $]_{2}$ system was no longer studied.

Free biotin lacks the physical hindrance of biotin conjugated to a large PEG polymer, being able to occupy the binding pockets of avidin more easily, which leads to hydrogel surface
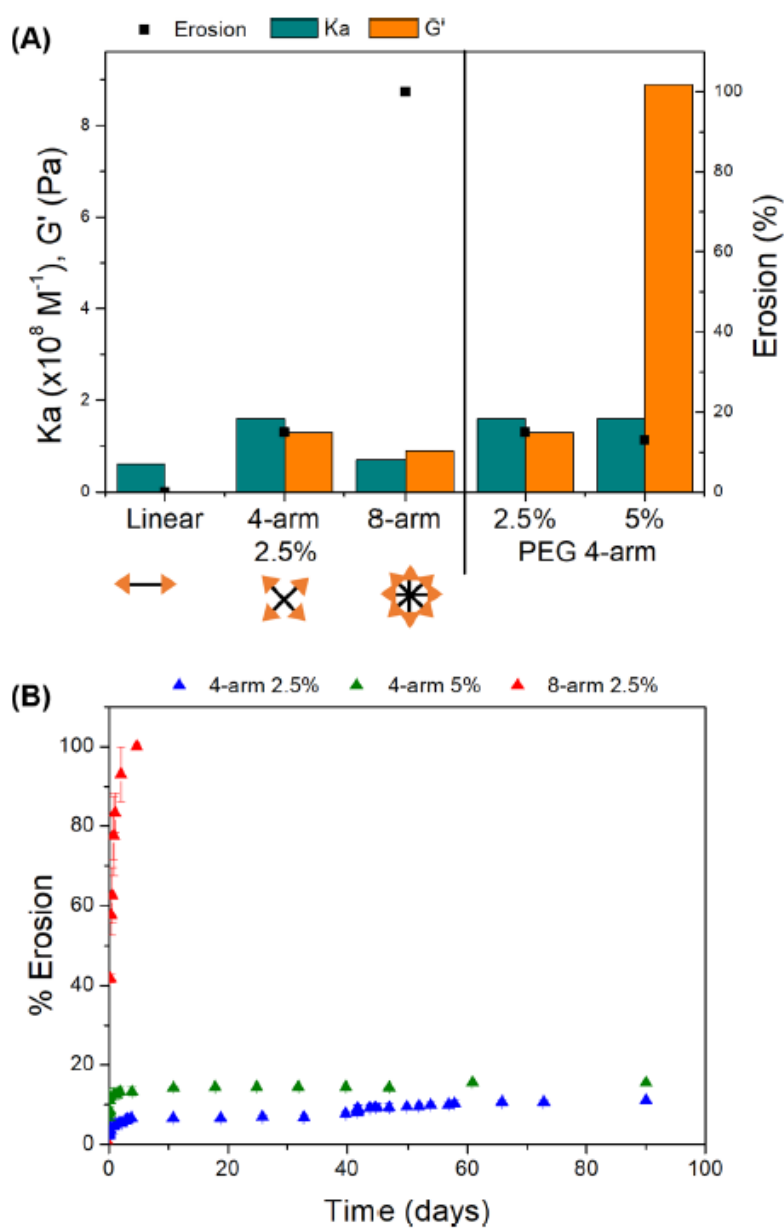

Figure 2. Properties of avidin-biotin hydrogels. (A) Comparison of the affinity constant $(\mathrm{Ka})$, erosion percentage (at $5 \mathrm{~h}$ ), and storage modulus $\left(G^{\prime}\right)$ for the avidin/PEG-[biotin] hydrogels. Erosion profiles (B) of avidin/biotin hydrogels in terms of concentration (2.5\% vs 5\%) and multivalency (four-arm vs eight-arm PEG at 2.5\%). (stdev corresponds to two replicates).

erosion. When adding free biotin $(2 \mathrm{mg} / \mathrm{mL})$ to $2.5 \%$ avidin/ PEG-[biotin $]_{4}$ hydrogels, an increase in erosion is observed, until the hydrogel completely dissolves into solution after 16 days (Figure 1D,E). The control avidin/PEG-[biotin $]_{4}$ hydrogel in the presence of PBS alone presents a $15 \%$ erosion after 20 days. Previous authors also observed faster hydrogel dissolution in the presence of nonconjugated biotin. ${ }^{34,38}$ The avidin/PEG-[biotin $]_{4}$ hydrogel was also characterized by ATR-FTIR, and it is possible to observe interactions between avidin and biotin that contribute for hydrogel formation (Figure S3).

Taken together, our data further confirm that the driving force for hydrogel formation is the affinity between avidin and biotin. In addition, it establishes that both affinity of the avidin-PEG system and multivalency are critical parameters to provide enough physical interactions between the two components to yield a macroscopic self-supportive gel.

3.2. Properties of Avidin/PEG-Biotin Hydrogels. Considering that only avidin/PEG-[biotin $]_{4}$ and avidin/PEG[biotin $]_{8}$ systems yielded self-supported gels, these materials were further characterized. The mechanical properties and 
(A)

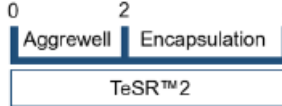

(B)

$$
\text { DAY } 0 \quad \text { DAY } 2
$$

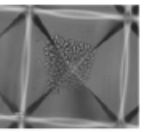

DAY 2

(C)

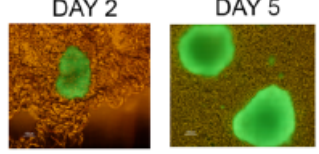

(D)

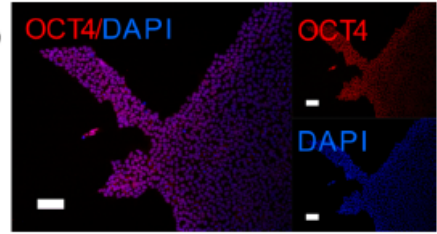

(E)

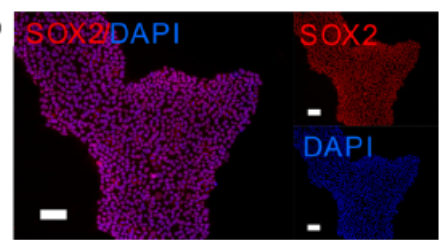

(F)

\begin{tabular}{|c|c|c|}
\hline Aggrewell & Encapsulation & Replating \\
\hline $\mathrm{TeSR}^{\mathrm{TM}} 2$ & & \\
\hline
\end{tabular}

(G)

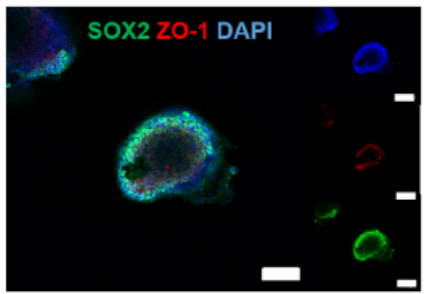

(H)

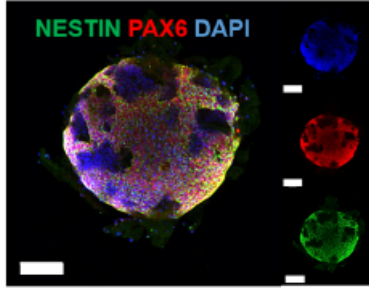

(I)

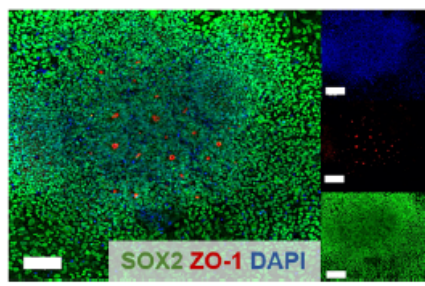

(J)

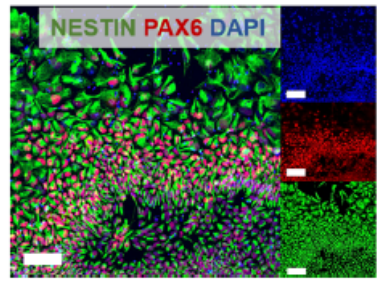

Figure 3. hiPSC encapsulated in avidin/PEG-[biotin $]_{4}$ hydrogels. (A-E) Pluripotency and viability assessment of encapsulated cells using xenofree TeSR2 expansion medium. (A) Graphical representation of the culture period of hiPSC aggregates encapsulated in the hydrogel. (B,C) Aggregates were formed with an initial cell density of $1.250 \times 10^{3}$ cells/aggregate. After 2 days of expansion in microwells, aggregates were removed and encapsulated in the avidin-biotin affinity hydrogel. (C) Bright-field microscopy image with the green fluorescence channel open to depict the 3D aggregates encapsulated in the hydrogel. Calcein AM viability assay was performed at day 2 and day 5 of encapsulation. The fluorescence channel is used to detect green fluorescence from the metabolized calcein AM and corresponds to live cells. (D,E) After 5 days of encapsulation, cells were harvested and replated on Matrigel-coated plates to assess pluripotency maintenance. Immunocytochemistry was performed on pluripotency intracellular markers, namely, (D) OCT4 and (E) SOX2. Nuclei were counterstained with DAPI. (F-J) Neural differentiation of encapsulated cells using xeno-free Essential 6 medium. (F) Graphical representation of the neural differentiation protocol. hiPSC aggregates were formed as in the previous case. After 2 days, aggregates were encapsulated in the hydrogel and cultured with E6 medium to induce neural differentiation. After 14 days, aggregates were harvested from the hydrogel and replated on laminin-coated plates. $(\mathrm{G}, \mathrm{H}) \mathrm{Immunocytochemistry} \mathrm{of}$ hiPSC-harvested aggregates for neural differentiation markers: SOX2 (green) comarked with ZO-1 (red) and PAX6 (red) comarked with NESTIN (green). DAPI (blue) was used to counterstain nuclei. ( $I J)$ Immunocytochemistry of replated aggregates for neural differentiation markers: SOX2 (green) comarked with ZO-1 (red) and PAX6 (red) comarked with NESTIN (green). DAPI (blue) was used to counterstain nuclei.

erosion profile of the gels were considered as a function of the measured affinity constant (Figure 2A).

When maintaining the concentration of the hydrogel components constant $[2.5 \%(\mathrm{w} / \mathrm{v})]$, the multivalency effect was studied. The affinity between avidin/PEG-[biotin $]_{8}$ was determined as $7.1 \times 10^{7} \mathrm{M}^{-1}$, an order of magnitude lower than that for the avidin/PEG-[biotin] $]_{4}$ system. The avidin/ PEG-[biotin $]_{8}$ hydrogel was visibly weaker than the avidin/ PEG-[biotin] $]_{4}$ hydrogel, presenting a lower mechanical stability $\left(G^{\prime}=0.9 \mathrm{~Pa}\right)$. This also translated into a complete gel erosion after $5 \mathrm{~h}$ (Figure 2A,B). Physical hydrogels usually degrade by a surface-erosion model, as the cross-links are maintained by labile dynamic affinity interactions. ${ }^{34}$ As avidin has four biotin binding pockets per molecule, the PEG[biotin $]_{4}$ allowed the formation of a more precise, effective, and stable network than PEG-[biotin $]_{8}$. On the other hand, the gelation time can influence the observed properties. Other authors described an increased gelation time for the PEG hydrogel with eight-arm versus four-arm (6 and $2 \mathrm{~h}$, 
respectively). ${ }^{49}$ In our case, this effect was not relevant as gelation occurred instantly.

The effect of concentration $[2.5$ and $5 \%(\mathrm{w} / \mathrm{v})]$ was further studied for the avidin/PEG-[biotin] $]_{4}$ hydrogels. Both avidin/ PEG-[biotin] $]_{4}$ hydrogels were robust, and only $15 \%$ erosion was observed after 3 months (Figure 2A,B). In fact, the high affinity between avidin and biotin led to the formation of a nondegradable hydrogel over 3 months. The system described was far more stable over time than other avidin/linear PEGbiotin hydrogels described in the literature, which were completely degraded after 5 days, even at concentrations as high as $14 \%(\mathrm{w} / \mathrm{v}) \cdot{ }^{34}$ In terms of mechanical properties, the $2.5 \%$ avidin/PEG-[biotin $]_{4}$ hydrogels were weaker (average $G^{\prime}$ $=1.3 \mathrm{~Pa}$ in the plateau) than the $5 \%$ hydrogels (average $G^{\prime}=$ 8.9 $\mathrm{Pa}$ in the plateau) because of the lower mass content which results in less cross-links between the components (Figure 2A). The storage modulus value is comparable to some reported multimeric protein/PEG-conjugated affinity-triggered hydrogels (e.g., TIP1 (trimeric)/PEG-TIP1-binding peptide hydrogels $^{22,23}$ ). However, it was not possible to compare them to other avidin/biotin affinity hydrogels as the mechanical properties were not reported. The reported avidin/PEG[biotin $]_{4}$ hydrogels are weak hydrogels, whose assembly occurs spontaneously and under mild conditions, which makes them advantageous to be explored for in vitro expansion of stem cells and cell therapy.

Because of a higher affinity constant, stability over time, and better mechanical performance, the avidin/PEG-[biotin $]_{4}$ was chosen to proceed with this work. The morphology and microstructure of $2.5 \%$ avidin/PEG-[biotin $]_{4}$ hydrogels were analyzed by SEM, (Figure S5) and they presented a very porous inner structure, displaying large pores with $11.2 \pm 0.2$ $\mu \mathrm{m}$ diameter.

3.3. Stem Cell Encapsulation, Expansion, and Neural Commitment. Encapsulation is a very common application for affinity-triggered hydrogels, which have been explored for the encapsulation of chondrocytes, ${ }^{23}$ mesenchymal stem cells, ${ }^{22,50}$ PC-12 cells, murine adult neural stem cells, ${ }^{25}$ human umbilical vein embryonic cells, ${ }^{25,29}$ and adipose-derived stem cells, ${ }^{24,27}$ with high cell viability after different time lengths. However, only one other avidin/biotin hydrogel has been used for cell encapsulation, specifically human mesenchymal stromal cells. ${ }^{34}$ In this context, to the best of our knowledge, we advance for the first time an affinity-triggered hydrogel capable to support the encapsulation, expansion, and differentiation of human pluripotent stem cells. In fact, the encapsulation of pluripotent stem cell derivatives is a promising approach for cell replacement therapies.

The cell biocompatibility of $2.5 \%$ avidin/PEG-[biotin] ${ }_{4}$ hydrogels was first assessed (Figure S6). Fibroblasts were chosen as the target cells because of their robustness. ${ }^{51}$ Two types of toxicity were studied: indirect and direct. The indirect toxicity is studied if the material leaks any toxic byproducts into the medium. The supernatant containing the released byproducts was used to culture a fibroblast monolayer, and its viability was assessed by the MTT assay (Figure S6A). Fibroblasts showed $100 \%$ viability compared to the positive control. This was expected as all hydrogel components are biocompatible (avidin, biotin, and $\mathrm{PEG}^{10}$ ) and low erosion was observed for longer times than the one tested in this assay. Other avidin/PEG-[biotin] hydrogels also allowed for high cell viability after the encapsulation of human mesenchymal stromal cells. ${ }^{34}$
In comparison, the negative control (supernatant containing byproducts of latex) showed low cell viability (11.8\%). This toxic effect has been reported before, ${ }^{52}$ with higher toxicity after extraction with serum-free media and culture media with serum compared to that with distilled water and saline solution. Natural rubber latex contains Hevb1 and Hevb3 ${ }^{52}$ and other chemicals that are added during the manufacturing process, ${ }^{53}$ and they are the principal components responsible for latex hyper sensibility. In this assay, they are responsible for cell toxicity.

Direct toxicity is studied if the material had toxic effects on an already formed monolayer of cells. Fibroblasts cultured in contact with the hydrogel grew in a compact monolayer, with no morphology alterations (typical elongated shape) (Figure S6B). Furthermore, as the hydrogel is translucent, it is possible to observe well-shaped cells growing underneath the hydrogel, suggesting that the hydrogel does not prevent oxygen and nutrients from reaching the cells. In comparison, cells cultured in contact with latex died in the proximity of the material and adopted a round shape (Figure S6C).

After showing that the hydrogel was biocompatible, we next aimed to encapsulate hiPSC aggregates using the avidin/PEG[biotin $]_{4}$ hydrogel and assess its impact on the maintenance of a pluripotent phenotype (Figure 3A). Pluripotent stem cell encapsulation has been used to promote cell expansion and differentiation into specific phenotypes and is an ideal solution for cell replacement therapies. ${ }^{4-6}$ Stem cell encapsulation is used to increase local cell densities, decrease cell losses, and increase cell survival.

We started by first comparing encapsulation of single cells versus 3D aggregates for 5 days of expansion under xeno-free conditions. Our preliminary experiments demonstrated that even with the addition of the ROCK inhibitor, single cells rapidly lost viability when compared to the encapsulated aggregates (data not shown). Because the hydrogel does not contain any ECM components, we hypothesized that there is a lack of structural support, which is surpassed using the 3D approach in our system. As a result, a density of $1.3 \times 10^{3}$ cells/microwell was used to produce aggregates with a controlled size diameter. In Figure 3B, it is possible to observe the formation of the aggregates from day 0 to day 2 of culture using the xeno-free culture medium (TeSR2). Before the encapsulation process, cells were incubated with a solution of calcein AM diluted in TeSR2 culture medium. This step was performed to assess the viability through fluorescence microscopy. In Figure 3C, it is possible to observe the result before and after encapsulation (day 2), which demonstrates the viability of cells throughout the process. Also, encapsulated aggregates were comparable to nonencapsulated controls (Figure S7A). On day 5, the same procedure was repeated to demonstrate that cells would maintain their viability throughout 3 days of encapsulation. The viability is demonstrated by the conversion of the nonfluorescent calcein $\mathrm{AM}$ into a green fluorescent probe as the result of acetoxylmethyl ester hydrolysis by intracellular esterases (Figure 3C). Therefore, it is possible to conclude that aggregates did not experience problems regarding nutrient and gas diffusion inside the hydrogel throughout the expansion period. More importantly, cells were able to grow inside the hydrogel, as it is possible to observe and quantify from the fluorescent microscopy images (Figures $3 \mathrm{C}$ and $\mathrm{S7B}$ ). Importantly, the encapsulation and expansion of hiPSC aggregates in our system were performed under entirely 
defined, xeno-free conditions. One of the important design criteria to develop functional and clinically relevant cell culture platforms is the absence of serum or serum placements, which may contain xenogeneic factors. ${ }^{4,54}$ This decreases the potential of immunogenic risk in the translation to a clinical setting.

After 3 days of expansion, the aggregates were mechanically harvested from the hydrogel and replated onto Matrigel-coated plates to perform immunocytochemistry assays. As shown in Figure 3D,E, it is possible to observe that the replated cells were able to grow as colonies with typical morphology of undifferentiated pluripotent stem cells. Moreover, cells were positively stained for two intracellular pluripotency markers, OCT4 and SOX2, which are essential transcription factors used for somatic cell reprogramming toward an embryonic-like state. ${ }^{55}$ This was comparable to the nonencapsulated controls (Figure S8A). Together with NANOG, SOX2 and OCT4 are part of a complex regulatory network that controls gene expression for potency maintenance and embryonic development. ${ }^{56}$ For instance, OCT 4 was shown to be essential for the formation of the inner cell mass of the blastocyst. ${ }^{57}$ Downregulation of OCT 4 can induce pluripotent stem cells to differentiate into the trophoblast and, to a greater extent, toward primitive endoderm and mesoderm lineages. ${ }^{58}$ In the case of SOX2, the expression of this marker is initiated in the morula stages, and it is essential for neural lineage commitment, where it promotes the neuroectodermal fate by suppressing mesodermal regulator genes. ${ }^{59}$ Moreover, depletion or over expression of SOX2 can induce human pluripotent stem cells to differentiate toward the trophectoderm. ${ }^{60}$ Therefore, by the quantification of the expression of these two transcription factors (Figure S8B), it is possible to conclude that hiPSCs maintained their undifferentiated state, while being cultured under xeno-free conditions.

To further demonstrate the usefulness of our encapsulation system, we tested if cells could differentiate inside the hydrogel, and to this end, we induced neural differentiation after the encapsulation stage (Figure 3F). On day 14 of neural commitment, part of the aggregates was harvested from the hydrogel for immunocytochemistry analysis. Similarly, the rest of the aggregates were collected and replated in laminin-coated plates to assess the presence of hiPSC-derived neural progenitor cells (hiPSC-NP). From Figure 3G-J, it is possible to observe that both aggregates and replated cells positively costained for PAX6 and Nestin, which comprise a transcription factor for neuroectoderm specification and an intermediate filament protein expressed in undifferentiated cells from the central nervous system, respectively. ${ }^{61,62}$ Moreover, immunocytochemistry analysis demonstrated the presence of SOX2 and apical ZO1 markers, further revealing polarized structures within the aggregate, which are consistent with the formation of neuro-epithelial rosettes that recapitulate the neural tube formation in vivo. ${ }^{63,64}$ These structures were also observed in the replated cells, which confirms the substantial maturation of hiPSC-NP. ${ }^{65}$ Furthermore, we could not discern differences in rosette formation after replating encapsulated aggregates or nonencapsulated (control) aggregates following neural commitment (Figure S9). Only one example of an affinity-triggered hydrogel has been reported to allow the self-renewal and differentiation of neuronal-like PC-12 cells and dissociated murine adult neural stem cells as cells adopted typical neural morphologies after differentiation. ${ }^{25}$ By comparison, the results obtained in this work show that the avidin/PEG-[biotin $]_{4}$ hydrogel can be used as a support material for encapsulation, expansion, and neural commitment of hiPSCs, and, most importantly, we demonstrate for the first time that an affinitytriggered hydrogel can be successfully used to generate phenotypically mature neural progenitors under xeno-free conditions. This constitutes an important first step toward the development of cell replacement therapies, where such hydrogels could support and guide the effective integration of cells at the site of injury.

\section{CONCLUSIONS}

Affinity-triggered hydrogels have shown several applications in tissue engineering and drug delivery. Affinity interactions can be rationally explored to develop tailor-made hydrogels, exposing predictable design rules which correlate natural and strategic multivalency. In this work, PEG molecules with different multivalencies were conjugated to biotin and further mixed with avidin to yield hydrogels with different characteristics. The hydrogel avidin/PEG-[biotin $]_{4}$ was proven to be cell-compatible and was successfully used to encapsulate pluripotent stem cells and to induce neural lineage in a xeno-free medium. The results showed that the developed hydrogel has the potential to increase local cell densities, maintain cell viability, and support human iPSC expansion and differentiation. The affinity-triggered hydrogel was able to encapsulate and sustain, for the first time, the commitment of pluripotent stem cells into phenotypically mature neural progenitors under xeno-free conditions. This technology could be further translated into a broader application in neural cell replacement therapies, such as in Parkinson's disease. Such an approach has allowed the design of multicomponent hydrogels inspired in nature and biology, which have proven to be important tools for the noninvasive and mild cell encapsulation, a requisite for tissue and cell therapies.

\section{ASSOCIATED CONTENT}

\section{s Supporting Information}

The Supporting Information is available free of charge at https://pubs.acs.org/doi/10.1021/acs.biomac.0c00473.

Characterization of multivalent PEG-biotin for hydrogel formation (FTIR-ATR; MST); properties of avidin/ PEG-biotin hydrogels (FTIR-ATR; rheology and SEM analysis); stem cell encapsulation, expansion, and neural commitment (hydrogel biocompatibility); analysis of total calcein intensity for encapsulated aggregates; pluripotency assessment of nonencapsulated aggregates; and neural differentiation of nonencapsulated aggregates replated at day 12 on Matrigel-coated plates (PDF)

\section{AUTHOR INFORMATION}

\section{Corresponding Authors}

Ana Sofia Pina - UCIBIO, Departamento de Quimica, Faculdade de Cîncias e Tecnologia, Universidade NOVA de Lisboa, 2829-516 Caparica, Portugal; Email: ana.pina@ fct.unl.pt

Ana Cecília A. Roque - UCIBIO, Departamento de Quimica, Faculdade de Ciencias e Tecnologia, Universidade NOVA de Lisboa, 2829-516 Caparica, Portugal; $\odot$ orcid.org/00000002-4586-3024; Email: cecilia.roque@fct.unl.pt 


\section{Authors}

Cláudia S. M. Fernandes - UCIBIO, Departamento de Quimica, Faculdade de Cîncias e Tecnologia, Universidade NOVA de Lisboa, 2829-516 Caparica, Portugal

André L. Rodrigues - Department of Bioengineering, iBBInstitute for Bioengineering and Biosciences, Instituto Superior Ténico, Universidade de Lisboa, 049-001 Lisboa, Portugal

Vitor D. Alves - LEAF, Linking Landscape, Environment, Agriculture and Food, Instituto Superior de Agronomia, Universidade de Lisboa, 1349-017 Lisboa, Portugal

Tiago G. Fernandes - Department of Bioengineering, $i B B-$ Institute for Bioengineering and Biosciences, Instituto Superior Técnico, Universidade de Lisboa, 049-001 Lisboa, Portugal

Complete contact information is available at:

https://pubs.acs.org/10.1021/acs.biomac.0c00473

\section{Author Contributions}

C.S.F.M., T.G.F., A.S.P., and A.C.A.R designed the experiments and wrote the manuscript. C.S.F.M. performed the experiments. C.S.F.M., A.L.R., and T.G.F. performed the cellbased assays. C.S.F.M., V.D.A., and A.S.P. performed the rheological experiments. All the authors analyzed the data.

\section{Notes}

The authors declare no competing financial interest.

\section{ACKNOWLEDGMENTS}

This work was financed by FCT/MEC (PTDC/BII-BIO/ 28878/2017, UIDB/04378/2020, UID/QUI/50006/2019, and UID/AGR/04129/2019) and cofinanced by the ERDF under the PT2020 Partnership Agreement (POCI-01-0145FEDER-007728 \& LISBOA-01-0145-FEDER-028878). The authors thank FCT/MEC for the research fellowship SFRH/ BPD $/ 97585 / 2013$ for A.S.P., PD/BD/105871/2014 for C.S.M.F, and PD/BD/135524/2018 for A.L.R. The authors would like to acknowledge the Laboratorio de Análises (FCTNOVA) for the ICP analysis and the BioLab (FCT-NOVA) for the MST assays.

\section{REFERENCES}

(1) Prince, E.; Kumacheva, E. Design and Applications of ManMade Biomimetic Fibrillar Hydrogels. Nat. Rev. Mater. 2019, 4, 99115 .

(2) Hussey, G. S.; Dziki, J. L.; Badylak, S. F. Extracellular MatrixBased Materials for Regenerative Medicine. Nat. Rev. Mater. 2018, 3, 159-173.

(3) Custódio, C. A.; Reis, R. L.; Mano, J. F. Engineering Biomolecular Microenvironments for Cell Instructive Biomaterials. Adv. Healthcare Mater. 2014, 3, 797-810.

(4) Adil, M. M.; Rodrigues, G. M. C.; Kulkarni, R. U.; Rao, A. T.; Chernavsky, N. E.; Miller, E. W.; Schaffer, D. V. Efficient Generation of hPSC-Derived Midbrain Dopaminergic Neurons in a Fully Defined, Scalable, 3D Biomaterial Platform. Sci. Rep. 2017, 7, 40573.

(5) Lin, H.; Li, Q.; Leia, Y. An Integrated Miniature Bioprocessing for Personalized Human Induced Pluripotent Stem Cell Expansion and Differentiation into Neural Stem Cells. Sci. Rep. 2017, 7, 4019140198.

(6) Lei, Y.; Schaffer, D. V. A Fully Defined and Scalable 3D Culture System for Human Pluripotent Stem Cell Expansion and Differentiation. Proc. Natl. Acad. Sci. 2013, 110, E5039-E5048.

(7) Adil, M. M.; Vazin, T.; Ananthanarayanan, B.; Rodrigues, G. M. C.; Rao, A. T.; Kulkarni, R. U.; Miller, E. W.; Kumar, S.; Schaffer, D. V. Engineered Hydrogels Increase the Post-Transplantation Survival of Encapsulated hESC-Derived Midbrain Dopaminergic Neurons. Biomaterials 2017, 136, 1-11.
(8) Cai, L.; Heilshorn, S. C. Designing ECM-Mimetic Materials Using Protein Engineering. Acta Biomater. 2014, 10, 1751-1760.

(9) Chai, C.; Leong, K. W. Biomaterials Approach to Expand and Direct Differentiation of Stem Cells. Mol. Ther. 2007, 15, 467-480.

(10) Jonker, A. M.; Löwik, D. W. P. M.; Van Hest, J. C. M. Peptideand Protein-Based Hydrogels. Chem. Mater. 2012, 24, 759-773.

(11) Dawson, E.; Mapili, G.; Erickson, K.; Taqvi, S.; Roy, K. Biomaterials for Stem Cell Differentiation. Adv. Drug Deliv. Rev. 2008, $60,215-228$

(12) Koetting, M. C.; Peters, J. T.; Steichen, S. D.; Peppas, N. A. Stimulus-Responsive Hydrogels: Theory, Modern Advances, and Applications. Mater. Sci. Eng. R 2015, 93, 1-49.

(13) Edalat, F.; Bae, H.; Manoucheri, S.; Cha, J. M.; Khademhosseini, A. Engineering Approaches Toward Deconstructing and Controlling the Stem Cell Environment. Ann. Biomed. Eng. 2012, 40, 1301-1315.

(14) Sengupta, D.; Heilshorn, S. C. Protein-Engineered Biomaterials: Highly Tunable Tissue Engineering Scaffolds. Tissue Eng. B Rev. 2010, 16, 285-293.

(15) Hinderer, S.; Layland, S. L.; Schenke-Layland, K. ECM and ECM-like Materials - Biomaterials for Applications in Regenerative Medicine and Cancer Therapy. Adv. Drug Deliv. Rev. 2016, 97, 260269.

(16) Huang, G.; Li, F.; Zhao, X.; Ma, Y.; Li, Y.; Lin, M.; Jin, G.; Lu, T. J.; Genin, G. M.; Xu, F. Functional and Biomimetic Materials for Engineering of the Three-Dimensional Cell Microenvironment. Chem. Rev. 2017, 117, 12764-12850.

(17) Lutolf, M. P.; Hubbell, J. A. Synthetic Biomaterials as Instructive Extracellular Microenvironments for Morphogenesis in Tissue Engineering. Nat. Biotechnol. 2005, 23, 47-55.

(18) Goor, O. J. G. M.; Hendrikse, S. I. S.; Dankers, P. Y. W.; Meijer, E. W. From Supramolecular Polymers to Multi-Component Biomaterials. Chem. Soc. Rev. 2017, 46, 6621-6637.

(19) Ramakers, B. E. I.; van Hest, J. C. M.; Löwik, D. W. P. M. Molecular Tools for the Construction of Peptide-Based Materials. Chem. Soc. Rev. 2014, 43, 2743-2756.

(20) Kopeček, J.; Yang, J. Smart Self-Assembled Hybrid Hydrogel Biomaterials. Angew. Chem., Int. Ed. Engl. 2012, 51, 7396-7417.

(21) Clegg, J. R.; Peppas, N. A. Molecular Recognition with Soft Biomaterials. Soft Matter 2020, 16, 856-869.

(22) Wang, J.; Zhang, J.; Zhang, X.; Zhou, H. A Protein-Based Hydrogel for in Vitro Expansion of Mesenchymal Stem Cells. PLoS One 2013, 8, No. e75727.

(23) Ito, F.; Usui, K.; Kawahara, D.; Suenaga, A.; Maki, T.; Kidoaki, S.; Suzuki, H.; Taiji, M.; Itoh, M.; Hayashizaki, Y.; Matsuda, T. Reversible Hydrogel Formation Driven by Protein-Peptide-Specific Interaction and Chondrocyte Entrapment. Biomaterials 2010, 31, 5866.

(24) Parisi-Amon, A.; Mulyasasmita, W.; Chung, C.; Heilshorn, S. C. Protein-Engineered Injectable Hydrogel to Improve Retention of Transplanted Adipose-Derived Stem Cells. Adv. Healthcare Mater. 2013, 2, 428-432.

(25) Wong Po Foo, C. T. S.; Seok Lee, J.; Mulyasasmita, W.; Parisiamon, A.; Heilshorn, S. C. Two-Component Protein-Engineered Physical Hydrogels for Cell Encapsulation. Proc. Natl. Acad. Sci. 2009, $106,22067-22072$

(26) Mulyasasmita, W.; Cai, L.; Dewi, R. E.; Jha, A.; Ullmann, S. D.; Luong, R. H.; Huang, N. F.; Heilshorn, S. C. Avidity-Controlled Hydrogels for Injectable Co-Delivery of Induced Pluripotent Stem Cell-Derived Endothelial Cells and Growth Factors. J. Controlled Release 2014, 191, 71-81.

(27) Cai, L.; Dewi, R. E.; Heilshorn, S. C. Injectable Hydrogels with in Situ Double Network Formation Enhance Retention of Transplanted Stem Cells. Adv. Funct. Mater. 2015, 25, 1344-1351.

(28) Fernandes, C. S. M.; Pina, A. S.; Moura Barbosa, A. J.; Padrão, I.; Duarte, F.; Teixeira, C. A. S.; Alves, V.; Gomes, P.; Fernandes, T. G.; Carvalho Dias, A. M. G.; Roque, A. C. A. Affinity-Triggered Assemblies Based on a Designed Peptide-Peptide Affinity Pair. Biotechnol. J. 2019, 14, 1800559. 
(29) Ehrbar, M.; Schoenmakers, R.; Christen, E. H.; Fussenegger, M.; Weber, W. Drug-Sensing Hydrogels for the Inducible Release of Biopharmaceuticals. Nat. Mater. 2008, 7, 800-804.

(30) Feng, Q.; Xu, J.; Zhang, K.; Yao, H.; Zheng, N.; Zheng, L.; Wang, J.; Wei, K.; Xiao, X.; Qin, L.; Bian, L. Dynamic and CellInfiltratable Hydrogels as Injectable Carrier of Therapeutic Cells and Drugs for Treating Challenging Bone Defects. ACS Cent. Sci. 2019, 5, $440-450$.

(31) Feng, Q.; Wei, K.; Lin, S.; Xu, Z.; Sun, Y.; Shi, P.; Li, G.; Bian, L. Mechanically Resilient, Injectable, and Bioadhesive Supramolecular Gelatin Hydrogels Crosslinked by Weak Host-Guest Interactions Assist Cell in Filtration and in Situ Tissue Regeneration. Biomaterials 2016, 101, 217-228.

(32) Okesola, B. O.; Mata, A. Multicomponent Self-Assembly as a Tool to Harness New Properties from Peptides and Proteins in Material Design. Chem. Soc. Rev. 2018, 47, 3721-3736.

(33) Wu, J.; Li, P.; Dong, C.; Jiang, H.; Xue, B.; Gao, X.; Qin, M.; Wang, W.; Chen, B.; Cao, Y. Rationally Designed Synthetic Protein Hydrogels with Predictable Mechanical Properties. Nat. Commun. 2018, 9, 620 .

(34) Thompson, M. S.; Tsurkan, M. V.; Chwalek, K.; Bornhauser, M.; Schlierf, M.; Werner, C.; Zhang, Y. Self-Assembling Hydrogels Crosslinked Solely by Receptor-Ligand Interactions: Tunability, Rationalization of Physical Properties, and 3D Cell Culture. Chem.-Eur. J. 2015, 21, 3178-3182.

(35) Barbucci, R.; Magnani, A.; Roncolini, C.; Silvestri, S. Antigenantibody Recognition by Fourier Transform IR Spectroscopy/ attenuated Total Reflection Studies: Biotin-avidin Complex as an Example. Biopolymers 1991, 31, 827-834.

(36) Wilchek, M. My Life with Affinity. Protein Sci. 2008, 13, 30663070.

(37) Liu, Y.; Liu, J.; Xu, J.; Feng, S.; Davis, T. P. Biodegradable PEG Hydrogels Cross-Linked Using Biotin-Avidin Interactions. Aust. J. Chem. 2010, 63, 1413-1417.

(38) Cui, Y.; Li, Y.; Duan, Q.; Kakuchi, T. Preparation of Hyaluronic Acid Micro-Hydrogel by Biotin-Avidin-Specific Bonding for Doxorubicin-Targeted Delivery. Appl. Biochem. Biotechnol. 2013, 169, 239249.

(39) International Organization for Standardization-ISO. ISO 10993-12: Biological Evaluation of Medical Devices. In Geneva: ISO, 1996; p Part 12: Sample preparation and reference material.

(40) International Organization for Standardization-ISO. ISO 10993-5: Biological Evaluation of Medical Devices. In Geneva: ISO, 1999; p part 5: Tests for cytotoxicity: In vitro methods.

(41) Beers, J.; Gulbranson, D. R.; George, N.; Siniscalchi, L. I.; Jones, J.; Thomson, J. A.; Chen, G. Passaging and Colony Expansion of Human Pluripotent Stem Cells by Enzyme-Free Dissociation in Chemically Defined Culture Conditions. Nat. Protoc. 2012, 7, 20292040.

(42) Rodrigues, C. A. V.; Diogo, M. M.; Da Silva, C. L.; Cabral, J. M. S. Microcarrier Expansion of Mouse Embryonic Stem Cell-Derived Neural Stem Cells in Stirred Bioreactors. Biotechnol. Appl. Biochem. 2011, 58, 231-242.

(43) Hytönen, V. P.; Laitinen, O. H.; Airenne, T. T.; Kidron, H.; Meltola, N. J.; Porkka, E. J.; Hörhä, J.; Paldanius, T.; Määttä, J. A. E.; Nordlund, H. R.; Johnson, M. S.; Salminen, T. A.; Airenne, K. J.; Yläherttuala, S.; Kulomaa, M. S. Efficient Production of Active Chicken Avidin Using a Bacterial Signal Peptide in Escherichia Coli. Biochem. J. 2004, 384, 385-390.

(44) Palma, S. I. C. J.; Fernandes, A. R.; Roque, A. C. A. An Affinity Triggered MRI Nanoprobe for $\mathrm{pH}-$ Dependent Cell Labeling. RSC Adv. 2016, 6, 113503-113512.

(45) Pina, A. S.; Lowe, C. R.; Roque, A. C. A. Challenges and Opportunities in the Purification of Recombinant Tagged Proteins. Biotechnol. Adv. 2014, 32, 366-381.

(46) Matos, M. J. B.; Pina, A. S.; Roque, A. C. A. Rational Design of Affinity Ligands for Bioseparation. J. Chromatogr. A 2020, 1619, 460871 .
(47) Branco, R. J. F.; Dias, A. M. G. C.; Roque, A. C. A. Understanding the Molecular Recognition between Antibody Fragments and Protein A Biomimetic Ligand. J. Chromatogr. A 2012, $1244,106-115$

(48) Santana, S. D. F.; Dhadge, V. L.; Roque, A. C. A. DextranCoated Magnetic Supports Modified with a Biomimetic Ligand for IgG Purification. ACS Appl. Mater. Interfaces 2012, 4, 5907-5914.

(49) Tan, H.; Defail, A.; Rubin, J. P.; Chu, C. R.; Marra, K. G. Novel Multi-Arm PEG-Based Hydrogels for Tissue Engineering. J. Biomed. Mater. Res., Part A 2010, 92, 979-987.

(50) Lu, H. D.; Soranno, D. E.; Rodell, C. B.; Kim, I. L.; Burdick, J. A. Secondary Photocrosslinking of Injectable Shear-Thinning Dockand-Lock Hydrogels. Adv. Healthcare Mater. 2013, 2, 1028-1036.

(51) Meske, V.; Albert, F.; Ohm, T. G. Cell Cultures of AutopyDerived Fibroblasts. Human Cell Culture Protocols; Methods in Molecular Medicine; Humana Press, 2005; Vol. 107, pp 111-123.

(52) Zhang, J.; Zhang, M.; Du, F.-S.; Li, Z.-C. Synthesis of Functional Polycaprolactones via Passerini Multicomponent Polymerization of 6-Oxohexanoic Acid and Isocyanides. Macromolecules 2016, $49,2592-2600$.

(53) Cormio, L.; Turjanmaa, K.; Talja, M.; Andersson, L. C.; Ruutu, M. Toxicity and Immediate Allergenieity of Latex Gloves. Clin. Exp. Allergy 1993, 23, 618-623.

(54) Swistowski, A.; Peng, J.; Han, Y.; Swistowska, A. M.; Rao, M. S.; Zeng, X. Xeno-Free Defined Conditions for Culture of Human Embryonic Stem Cells, Neural Stem Cells and Dopaminergic Neurons Derived from Them. PLoS One 2009, 4, No. e6233.

(55) Takahashi, K.; Tanabe, K; Ohnuki, M.; Narita, M.; Ichisaka, T.; Tomoda, K.; Yamanaka, S. Induction of Pluripotent Stem Cells from Adult Human Fibroblasts by Defined Factors. Cell 2007, 131, 861-872.

(56) Kashyap, V.; Rezende, N. C.; Scotland, K. B.; Shaffer, S. M.; Persson, J. L.; Gudas, L. J.; Mongan, N. P. Regulation of Stem Cell Pluripotency and Differentiation Involves a Mutual Regulatory Circuit of the NANOG, OCT4, and SOX2 Pluripotency Transcription Factors with Polycomb Repressive Complexes and Stem Cell microRNAs. Stem Cell. Dev. 2009, 18, 1093-1108.

(57) Rizzino, A.; Wuebben, E. Sox2/Oct4: A Delicately Balanced Partnership in Pluripotent Stem Cells and Embryogenesis. Biochim. Biophys. Acta 2016, 1859, 790-791.

(58) Shi, G.; Jin, Y. Role of Oct4 in Maintaining and Regaining Stem Cell Pluripotency. Stem Cell Res. Ther. 2010, 1, 39.

(59) Wang, Z.; Oron, E.; Nelson, B.; Razis, S.; Ivanova, N. Distinct Lineage Specification Roles for NANOG, OCT4, and SOX2 in Human Embryonic Stem Cells. Cell Stem Cell 2012, 10, 440-454.

(60) Adachi, K.; Suemori, H.; Yasuda, S.; Nakatsuji, N.; Kawase, E. Role of SOX2 in Maintaining Pluripotency of Human Embryonic Stem Cells. Genes Cells 2010, 15, 455-470.

(61) Zhang, X.; Huang, C. T.; Chen, J.; Pankratz, M. T.; Xi, J.; Li, J.; Yang, Y.; Lavaute, T. M.; Li, X.-J.; Ayala, M.; Bondarenko, G. I.; Du, Z.-W.; Jin, Y.; Golos, T. G.; Zhang, S.-C. Pax6 Is a Human Neuroectoderm Cell Fate Determinant. Cell Stem Cell 2010, 7, 90100.

(62) Suzuki, S.; Namiki, J.; Shibata, S.; Mastuzaki, Y.; Okano, H. The Neural Stem/progenitor Cell Marker Nestin Is Expressed in Proliferative Endothelial Cells, but Not in Mature Vasculature. J. Histochem. Cytochem. 2010, 58, 721-730.

(63) Fernandes, T. G.; Duarte, S. T.; Ghazvini, M.; Gaspar, C.; Santos, D. C.; Porteira, A. R.; Rodrigues, G. M. C.; Haupt, S.; Rombo, D. M.; Armstrong, J.; Sebastião, A. M.; Gribnau, J.; Garcia-Cazorla, À.; Brüstle, O.; Henrique, D.; Cabral, J. M. S.; Diogo, M. M. Neural Commitment of Human Pluripotent Stem Cells under Defined Conditions Recapitulates Neural Development and Generates Patient-Specific Neural Cells. Biotechnol. J. 2015, 10, 1578-1588.

(64) Chambers, S. M.; Fasano, C. A.; Papapetrou, E. P.; Tomishima, M.; Sadelain, M.; Studer, L. Highly Efficient Neural Conversion of Human ES and iPS Cells by Dual Inhibition of SMAD Signaling. Nat. Protoc. 2009, 27, 275-280. 
(29) Ehrbar, M.; Schoenmakers, R.; Christen, E. H.; Fussenegger, M.; Weber, W. Drug-Sensing Hydrogels for the Inducible Release of Biopharmaceuticals. Nat. Mater. 2008, 7, 800-804.

(30) Feng, Q.; Xu, J.; Zhang, K.; Yao, H.; Zheng, N.; Zheng, L.; Wang, J.; Wei, K.; Xiao, X.; Qin, L.; Bian, L. Dynamic and CellInfiltratable Hydrogels as Injectable Carrier of Therapeutic Cells and Drugs for Treating Challenging Bone Defects. ACS Cent. Sci. 2019, 5, $440-450$.

(31) Feng, Q.; Wei, K.; Lin, S.; Xu, Z.; Sun, Y.; Shi, P.; Li, G.; Bian, L. Mechanically Resilient, Injectable, and Bioadhesive Supramolecular Gelatin Hydrogels Crosslinked by Weak Host-Guest Interactions Assist Cell in Filtration and in Situ Tissue Regeneration. Biomaterials 2016, 101, 217-228.

(32) Okesola, B. O.; Mata, A. Multicomponent Self-Assembly as a Tool to Harness New Properties from Peptides and Proteins in Material Design. Chem. Soc. Rev. 2018, 47, 3721-3736.

(33) Wu, J.; Li, P.; Dong, C.; Jiang, H.; Xue, B.; Gao, X.; Qin, M.; Wang, W.; Chen, B.; Cao, Y. Rationally Designed Synthetic Protein Hydrogels with Predictable Mechanical Properties. Nat. Commun. 2018, 9, 620 .

(34) Thompson, M. S.; Tsurkan, M. V.; Chwalek, K.; Bornhauser, M.; Schlierf, M.; Werner, C.; Zhang, Y. Self-Assembling Hydrogels Crosslinked Solely by Receptor-Ligand Interactions: Tunability, Rationalization of Physical Properties, and 3D Cell Culture. Chem.-Eur. J. 2015, 21, 3178-3182.

(35) Barbucci, R.; Magnani, A.; Roncolini, C.; Silvestri, S. Antigenantibody Recognition by Fourier Transform IR Spectroscopy/ attenuated Total Reflection Studies: Biotin-avidin Complex as an Example. Biopolymers 1991, 31, 827-834.

(36) Wilchek, M. My Life with Affinity. Protein Sci. 2008, 13, 30663070 .

(37) Liu, Y.; Liu, J.; Xu, J.; Feng, S.; Davis, T. P. Biodegradable PEG Hydrogels Cross-Linked Using Biotin-Avidin Interactions. Aust. J. Chem. 2010, 63, 1413-1417.

(38) Cui, Y.; Li, Y.; Duan, Q.; Kakuchi, T. Preparation of Hyaluronic Acid Micro-Hydrogel by Biotin-Avidin-Specific Bonding for Doxorubicin-Targeted Delivery. Appl. Biochem. Biotechnol. 2013, 169, 239249.

(39) International Organization for Standardization-ISO. ISO 10993-12: Biological Evaluation of Medical Devices. In Geneva: ISO, 1996; p Part 12: Sample preparation and reference material.

(40) International Organization for Standardization-ISO. ISO 10993-5: Biological Evaluation of Medical Devices. In Geneva: ISO, 1999; p part 5: Tests for cytotoxicity: In vitro methods.

(41) Beers, J.; Gulbranson, D. R.; George, N.; Siniscalchi, L. I.; Jones, J.; Thomson, J. A.; Chen, G. Passaging and Colony Expansion of Human Pluripotent Stem Cells by Enzyme-Free Dissociation in Chemically Defined Culture Conditions. Nat. Protoc. 2012, 7, 20292040.

(42) Rodrigues, C. A. V.; Diogo, M. M.; Da Silva, C. L.; Cabral, J. M. S. Microcarrier Expansion of Mouse Embryonic Stem Cell-Derived Neural Stem Cells in Stirred Bioreactors. Biotechnol. Appl. Biochem. 2011, 58, 231-242.

(43) Hytönen, V. P.; Laitinen, O. H.; Airenne, T. T.; Kidron, H.; Meltola, N. J.; Porkka, E. J.; Hörhä, J.; Paldanius, T.; Määttä, J. A. E.; Nordlund, H. R.; Johnson, M. S.; Salminen, T. A.; Airenne, K. J.; Yläherttuala, S.; Kulomaa, M. S. Efficient Production of Active Chicken Avidin Using a Bacterial Signal Peptide in Escherichia Coli. Biochem. J. 2004, 384, 385-390.

(44) Palma, S. I. C. J.; Fernandes, A. R.; Roque, A. C. A. An Affinity Triggered MRI Nanoprobe for $\mathrm{pH}$ - Dependent Cell Labeling. RSC Adv. 2016, 6, 113503-113512.

(45) Pina, A. S.; Lowe, C. R.; Roque, A. C. A. Challenges and Opportunities in the Purification of Recombinant Tagged Proteins. Biotechnol. Adv. 2014, 32, 366-381.

(46) Matos, M. J. B.; Pina, A. S.; Roque, A. C. A. Rational Design of Affinity Ligands for Bioseparation. J. Chromatogr. A 2020, 1619, 460871 .
(47) Branco, R. J. F.; Dias, A. M. G. C.; Roque, A. C. A Understanding the Molecular Recognition between Antibody Frag ments and Protein A Biomimetic Ligand. J. Chromatogr. A 2012, $1244,106-115$

(48) Santana, S. D. F.; Dhadge, V. L.; Roque, A. C. A. DextranCoated Magnetic Supports Modified with a Biomimetic Ligand for IgG Purification. ACS Appl. Mater. Interfaces 2012, 4, 5907-5914.

(49) Tan, H.; Defail, A.; Rubin, J. P.; Chu, C. R.; Marra, K. G. Novel Multi-Arm PEG-Based Hydrogels for Tissue Engineering. J. Biomed. Mater. Res., Part A 2010, 92, 979-987.

(50) Lu, H. D.; Soranno, D. E.; Rodell, C. B.; Kim, I. L.; Burdick, J. A. Secondary Photocrosslinking of Injectable Shear-Thinning Dockand-Lock Hydrogels. Adv. Healthcare Mater. 2013, 2, 1028-1036.

(51) Meske, V.; Albert, F.; Ohm, T. G. Cell Cultures of AutopyDerived Fibroblasts. Human Cell Culture Protocols; Methods in Molecular Medicine; Humana Press, 2005; Vol. 107, pp 111-123.

(52) Zhang, J.; Zhang, M.; Du, F.-S.; Li, Z.-C. Synthesis of Functional Polycaprolactones via Passerini Multicomponent Polymerization of 6-Oxohexanoic Acid and Isocyanides. Macromolecules 2016, $49,2592-2600$

(53) Cormio, L.; Turjanmaa, K.; Talja, M.; Andersson, L. C.; Ruutu, M. Toxicity and Immediate Allergenieity of Latex Gloves. Clin. Exp. Allergy 1993, 23, 618-623.

(54) Swistowski, A.; Peng, J.; Han, Y.; Swistowska, A. M.; Rao, M. S.; Zeng, X. Xeno-Free Defined Conditions for Culture of Human Embryonic Stem Cells, Neural Stem Cells and Dopaminergic Neurons Derived from Them. PLoS One 2009, 4, No. e6233.

(55) Takahashi, K.; Tanabe, K; Ohnuki, M.; Narita, M.; Ichisaka, T.; Tomoda, K.; Yamanaka, S. Induction of Pluripotent Stem Cells from Adult Human Fibroblasts by Defined Factors. Cell 2007, 131 861-872.

(56) Kashyap, V.; Rezende, N. C.; Scotland, K. B.; Shaffer, S. M.; Persson, J. L.; Gudas, L. J.; Mongan, N. P. Regulation of Stem Cell Pluripotency and Differentiation Involves a Mutual Regulatory Circuit of the NANOG, OCT4, and SOX2 Pluripotency Transcription Factors with Polycomb Repressive Complexes and Stem Cell microRNAs. Stem Cell. Dev. 2009, 18, 1093-1108.

(57) Rizzino, A.; Wuebben, E. Sox2/Oct4: A Delicately Balanced Partnership in Pluripotent Stem Cells and Embryogenesis. Biochim. Biophys. Acta 2016, 1859, 790-791.

(58) Shi, G.; Jin, Y. Role of Oct4 in Maintaining and Regaining Stem Cell Pluripotency. Stem Cell Res. Ther. 2010, 1, 39.

(59) Wang, Z.; Oron, E.; Nelson, B.; Razis, S.; Ivanova, N. Distinct Lineage Specification Roles for NANOG, OCT4, and SOX2 in Human Embryonic Stem Cells. Cell Stem Cell 2012, 10, 440-454.

(60) Adachi, K.; Suemori, H.; Yasuda, S.; Nakatsuji, N.; Kawase, E. Role of SOX2 in Maintaining Pluripotency of Human Embryonic Stem Cells. Genes Cells 2010, 15, 455-470.

(61) Zhang, X.; Huang, C. T.; Chen, J.; Pankratz, M. T.; Xi, J.; Li, J.; Yang, Y.; Lavaute, T. M.; Li, X.-J.; Ayala, M.; Bondarenko, G. I.; Du, Z.-W.; Jin, Y.; Golos, T. G.; Zhang, S.-C. Pax6 Is a Human Neuroectoderm Cell Fate Determinant. Cell Stem Cell 2010, 7, 90100 .

(62) Suzuki, S.; Namiki, J.; Shibata, S.; Mastuzaki, Y.; Okano, H. The Neural Stem/progenitor Cell Marker Nestin Is Expressed in Proliferative Endothelial Cells, but Not in Mature Vasculature. J. Histochem. Cytochem. 2010, 58, 721-730.

(63) Fernandes, T. G.; Duarte, S. T.; Ghazvini, M.; Gaspar, C.; Santos, D. C.; Porteira, A. R.; Rodrigues, G. M. C.; Haupt, S.; Rombo, D. M.; Armstrong, J.; Sebastião, A. M.; Gribnau, J.; Garcia-Cazorla, A.; Brüstle, O.; Henrique, D.; Cabral, J. M. S.; Diogo, M. M. Neural Commitment of Human Pluripotent Stem Cells under Defined Conditions Recapitulates Neural Development and Generates Patient-Specific Neural Cells. Biotechnol. J. 2015, 10, 1578-1588.

(64) Chambers, S. M.; Fasano, C. A.; Papapetrou, E. P.; Tomishima, M.; Sadelain, M.; Studer, L. Highly Efficient Neural Conversion of Human ES and iPS Cells by Dual Inhibition of SMAD Signaling. Nat. Protoc. 2009, 27, 275-280. 